\title{
A Proline Mimetic for the Design of New Stable Secondary Structures: Solvent-Dependent Amide Bond Isomerization of (S)-Indoline-2-carboxylic Acid Derivatives
}

\author{
Matteo Pollastrini, Filippo Lipparini, Luca Pasquinelli, Federica Balzano, Gloria Uccello Barretta, \\ Gennaro Pescitelli, and Gaetano Angelici*
}

Cite This: J. Org. Chem. 2021, 86, 7946-7954

Read Online

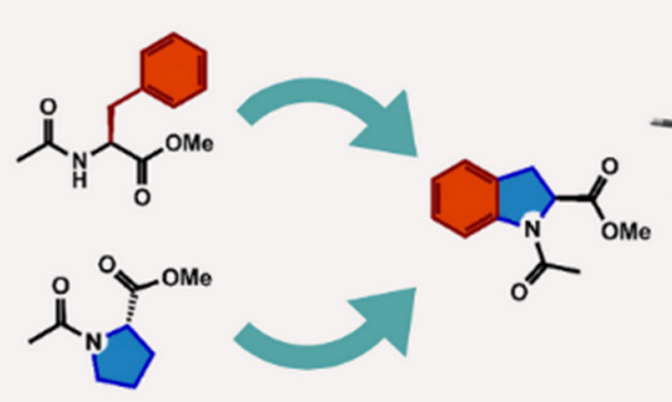

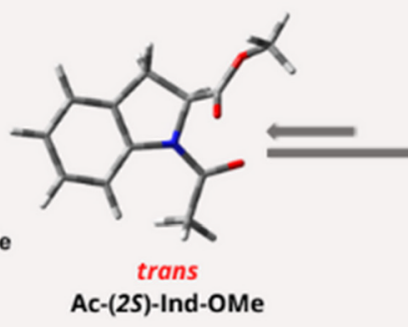

Balance is matter
of a Moment

ABSTRACT: A thorough experimental and computational study on the conformational properties of $(S)$-indoline-2-carboxylic acid derivatives has been conducted. Methyl $(S)$-1-acetylindoline-2-carboxylate, both a mimetic of proline and phenylalanine, shows a remarkable tendency toward the cis amide isomer when dissolved in polar solvents. This behavior is opposite to the general preference of proline for the trans isomer, making indoline-2-carboxylic acid a good candidate for the design of different secondary structures and new materials.

\section{INTRODUCTION}

Conformational diversity is Nature's way of disclosing important properties; therefore, a deeper understanding of the intrinsic conformational order of natural and unnatural amino acids is essential for the rational design of biomimetic compounds. Proline and phenylalanine are two important amino acids often involved, respectively, in protein conformational switching and aggregation phenomena. For proline and its analogues, the pioneering work of Wennemers' group showed that a deep knowledge of the conformational properties of model peptides in different environments, ${ }^{1}$ especially for the cis/trans isomerization equilibrium, can lead to a number of applications in catalysis ${ }^{2}$ or in the synthesis of collagene-like materials, ${ }^{3-5}$ as a tool for polyproline II crystal structure resolution ${ }^{6}$ or in the use of oligoprolines in supramolecular assembled materials. ${ }^{7,8}$ Regarding phenylalanine, since the groundbreaking studies by Gazit about the aggregation properties of amyloid peptides, 9,10 so many developments have taken place in nanobiotechnology, ${ }^{11,12}$ and biomaterials ${ }^{13}$ that it seems appropriate to refer to more extensive reviews. ${ }^{14-16}$ The deeper comprehension and combination of the many factors that control the cis/trans isomerization and aggregation, like $\mathrm{n} \rightarrow \pi^{*}$ interactions, ${ }^{17-24}$ $\pi-\pi$ stacking, ${ }^{25,26}$ or steric factors, ${ }^{27-31}$ have led to the study of many peptide analogues. For example, Tomasini's group developed oxazolidinone-containing peptides, ${ }^{32,33}$ showing that the Phe-D-Oxd moiety is a privileged scaffold for controlling the formation of supramolecular materials, ${ }^{34,35}$ thanks to the preferential trans conformation of generic Xaa-D-Oxd bonds and the presence of phenylalanine. Moreover, they recently developed new soft materials based on L-DOPA, ${ }^{36,37}$ a psychoactive analogue of phenylalanine, and in collaboration with them we could spot through chiroptical techniques the elusive $\pi$-helix motif attained by oligomers containing pyroglutamic acid, ${ }^{38}$ a proline mimetic. $(S)$-Indoline-2-carboxylic acid $((2 S)$-Ind) is an interesting case, as it is both a mimetic of L-proline and L-phenylalanine. (2S)-Ind can be considered as the result of the fusion of an aromatic ring to the pyrrolidine bond between $\mathrm{C} 4$ and $\mathrm{C} 5$ of proline. At the same time, $(2 S)$-Ind can also be seen as a phenylalanine with the side chain

Received: January 23, 2021

Published: June 3, 2021 
conformationally locked in a fixed orientation. Both these features make $(2 S)$-Ind a good candidate for the investigation of its conformational properties. Contrary to the many studied proline analogues with substituents at position C4 and C5, ${ }^{39-43}$ pseudoprolines, ${ }^{44}$ or other bicyclic proline derivatives, ${ }^{45,46}(2 S)$ Ind cannot undergo stabilization or destabilization by ring puckering, as the 5-membered ring is intrinsically quasiplanar.

The biological importance of kinetic and thermodynamic quantities of prolinamide conformational interconversions is well demonstrated, for example, by the extensive work of Fischer's group. ${ }^{47-51} \mathrm{Cis} /$ trans proline isomerization has indeed often been found as the rate-limiting step in the protein-folding processes. Regarding specifically $(2 S)$-Ind, an earlier explorative computational study of Torras et al. ${ }^{52}$ on the $N$-acetyl- $N^{\prime}$ methylamide derivative (Ac-(2S)-Ind-NHMe) investigated the structural role of the aromatic ring, highlighting that its presence further reduces the intrinsically low conformational flexibility of proline, giving higher preference for the cis state of the peptide bond involving the pyrrolidine nitrogen. However, the presence of a terminal secondary amide might have a strong influence on the conformation of the molecule, given the possibility of hydrogen bond formation. Consequently, in the conformational analysis of proline and its analogues, acetylated methyl esters or $N$-acetyl- $N^{\prime}, N^{\prime}$-dimethylamides are often preferred. ${ }^{53}$ For this reason we decided to investigate Ac- $(2 S)$-Ind-OMe (1) and the dimer Ac-(2S)-Ind-(2S)-Ind-OMe (2) (Scheme 1) to explore

Scheme 1. (Top) Cis-Trans Isomerization Equilibrium of the Amidic Bond in Ac-(2S)-Ind-OMe (1) and Major Torsional angles. (Bottom) Structure of Ac-(2S)-Ind-(2S)-Ind-OMe (2) Shown as the Major Cis-Cis Conformer, Relative to the Two $\omega$ Angles

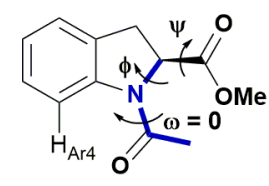

(1)-cis

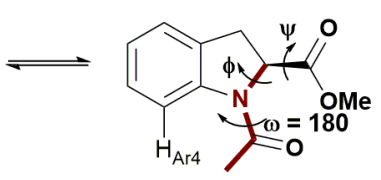

(1)-trans

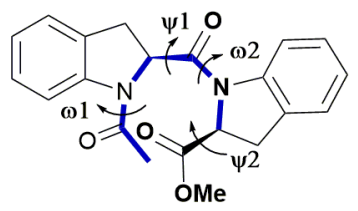

(2)-cis-cis the cis and trans isomers; the procedure is detailed in the Experimental Section. The capability to distinguish each signal is useful to study the physicochemical parameters of the equilibrium in solution. It was possible to evaluate the populations of cis and trans isomers, and consequently, the value of the cis-to-trans equilibrium constant $K_{\text {trans/cis }}$ at $25{ }^{\circ} \mathrm{C}$, through the ratio between the integrated areas of the two peaks corresponding to the $\mathrm{H} \alpha$ of the two isomers in the ${ }^{1} \mathrm{H}$ NMR spectrum, found between 4.1 and $5.2 \mathrm{ppm}$ (Figure 1 and Table

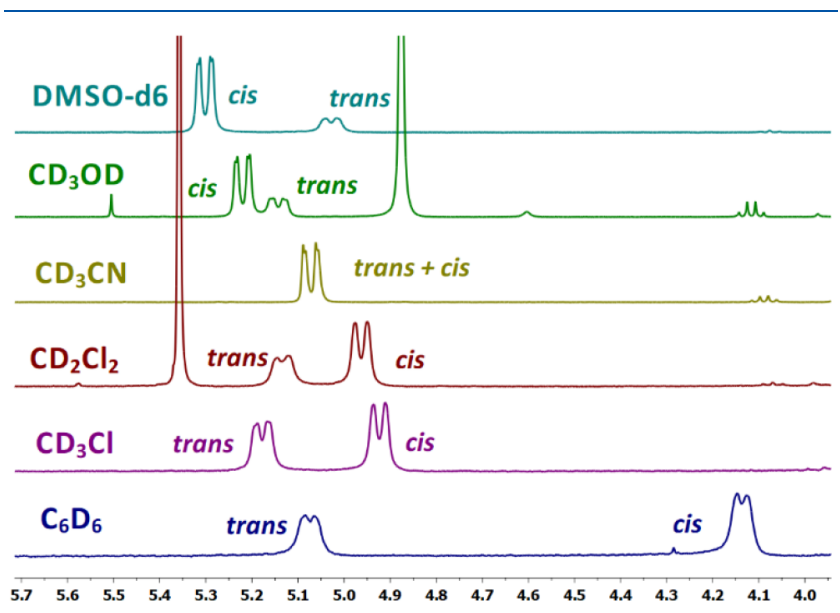

Figure 1. ${ }^{1} \mathrm{H}$ NMR in the $\mathrm{H} \alpha$ region of a $0.1 \mathrm{M}$ solution of 1 in different solvents at $25^{\circ} \mathrm{C}$.

Table 1. $K_{\text {trans/cis }}$ of Ac-(2S)-Ind-OMe (1) Obtained from ${ }^{1} \mathrm{H}$ NMR Spectroscopy of 0.1M Solutions in Different Deuterated Solvents at $298 \mathrm{~K}$

\begin{tabular}{lcccc}
\multicolumn{1}{c}{ solvent } & $K_{\text {trans/cis }}$ & $\delta(\mathrm{ppm})$ trans $^{a}$ & $\delta(\mathrm{ppm})$ cis $^{a}$ & $\varepsilon_{\mathrm{r}}^{b}$ \\
$\mathrm{C}_{6} \mathrm{D}_{6}$ & 0.72 & 5.06 & 4.14 & 2.3 \\
$\mathrm{CDCl}_{3}$ & 0.87 & 5.17 & 4.91 & 4.8 \\
$\mathrm{CD}_{2} \mathrm{Cl}_{2}$ & 0.63 & 5.10 & 4.93 & 8.9 \\
$\mathrm{CD}_{3} \mathrm{OD}$ & 0.47 & 5.15 & 5.22 & 32.7 \\
$\mathrm{CD}_{3} \mathrm{CN}$ & $0.43^{c}$ & 5.04 & 5.04 & 37.5 \\
$\mathrm{DMSO}_{6}$ & 0.31 & 5.02 & 5.30 & 46.7
\end{tabular}

${ }^{a}$ Chemical shift values of the $\mathrm{H} \alpha$ of the trans and cis conformer. ${ }^{b}$ Solvent dielectric constant. ${ }^{c}$ For $\mathrm{CD}_{3} \mathrm{CN}, K_{\text {trans/cis }}$ was calculated through the ratio between the integrated areas of the $\mathrm{CH}_{3}$ acetamide signals of the two isomers.

1). The preferred species in a $0.1 \mathrm{M} \mathrm{CDCl}_{3}$ solution of $\mathbf{1}$ is the cis conformer, with a corresponding $K_{\text {trans/cis }}=0.87$. The conformational preference seems to be independent of the concentration, as the trans/cis ratio did not change analyzing 0.04 and $0.8 \mathrm{M}$ solutions of 1 in $\mathrm{CDCl}_{3}$. More interestingly, we observed a marked influence of the solvent polarity on the equilibrium (Figure 1 and Table 1). More polar solvents favor the prevalence of the cis conformer. Another interesting phenomenon, also evident in Figure 1, is that the signal of the $\mathrm{H} \alpha$ in the cis conformer moves significantly to lower frequencies depending on the polarity of the solvent, while the $\mathrm{H} \alpha$ signal corresponding to the trans conformer is less affected.

As it can be seen in Table 1, by testing several solvents, the trans/cis ratio spans from 0.72 in benzene- $d_{6}$ to 0.31 in DMSO$d_{6}$, depending on the dielectric constant $\left(\varepsilon_{\mathrm{r}}\right)$ of the solvent. This observation can be rationalized by assuming a larger dipole moment for the cis isomer than for the trans one, which results in 
a stabilization of the cis conformer by more polar solvents. ${ }^{54}$ The experimental $K_{\text {trans/cis }}$ values were fitted against an empirical correlation of the type defined by eq SI4 (see the Supporting Information, SI), which describes a solvent-dependent conformational equilibrium where the solvent is seen as a uniform dielectric with relative permittivity $\varepsilon_{\mathrm{r}}{ }^{55}$ A very good fit was observed for all solvents, except benzene, demonstrating that the equilibrium is indeed controlled by the solvent reaction field, while benzene is possibly capable of specific interactions with the solute aromatic ring.

Comparing the measured $K_{\text {trans/cis }}$ with those reported for AcPro-OMe, we can see that the nature of the solvent and the presence of the aromatic ring drastically affects the conformational equilibrium around the amide bond (Table 2). More

Table 2. Comparison of the $K_{\text {trans/cis }}$ of Ac-(2S)-Ind-OMe (1) and Ac-Pro-OMe in Different Solvents at $298 \mathrm{~K}$

\begin{tabular}{|cccc}
\multicolumn{1}{c}{ Хaa } & $\mathrm{CDCl}_{3}$ & DMSO- $d_{6}$ & $\mathrm{C}_{6} \mathrm{D}_{6}$ \\
Ac-Pro-OMe & $3.6^{53}$ & $3.8^{53}$ & $\sim 4.9^{56}$ \\
Ac-(2S)-Ind-OMe & 0.87 & 0.31 & 0.72 \\
\hline
\end{tabular}

importantly, contrary to most proline-mimetic compounds reported in the literature, 1 shows in solution an excess of the cisamide isomer which increases with the solvent dielectric constant.

To confirm the importance of solvent polarity in the stabilization of the cis conformer of $\mathbf{1}$, we performed a series of titrations. We observed that adding sequential amounts of $\mathrm{D}_{2} \mathrm{O}$ to a DMSO- $d_{6}$ solution of $\mathbf{1}$ did not affect at all the preference for the cis isomer, while adding portions of DMSO- $d_{6}$ to a solution of 1 dissolved in benzene- $d_{6}$ proportionally increased the population of the cis isomer. These experiments show that the conformational preference is dominated by the solvent polarity, as expected, rather than by solute-solvent hydrogen bonding.

With the aim of evaluating the thermodynamic parameters associated with the isomerization equilibrium in DMSO- $d_{6}$, we performed variable-temperature NMR experiments to be analyzed by the Van't Hoff equation. ${ }^{57}$ As can be seen in Figure 2 , the increase of temperature led to a coalescence of the cis/ trans $\mathrm{H} \alpha$ signals around $5.2 \mathrm{ppm}$ already at $60^{\circ} \mathrm{C}$, indicating a fast exchange between the two populations. However, the characteristic signal of the aromatic proton $\mathrm{H}_{\mathrm{Ar} 4 c i s}$, deshielded by

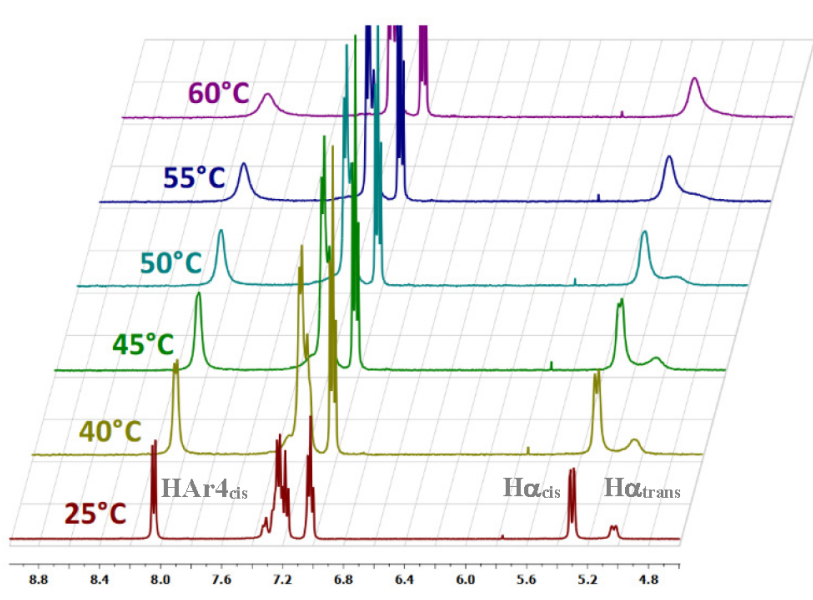

Figure 2. ${ }^{1} \mathrm{H}$ NMR of a $0.1 \mathrm{M}$ solution of $\mathbf{1}$ in DMSO- $d_{6}$ at different temperatures the proximate acetamide group when the amidic bond is in the cis conformation, remains anchored around $8.2 \mathrm{ppm}$, allowing the determination of $K_{\mathrm{eq}}$ at different temperatures. By plotting $\ln$ $K_{\text {eq }}$ vs $1 / T, \Delta H^{\circ}$ and $\Delta S^{\circ}$ can be obtained (see the SI). The estimated values are $\Delta H^{\circ}=+3.10 \mathrm{kcal} / \mathrm{mol}$ and $\Delta S^{\circ}=+8.2 \mathrm{cal} /$ molK for the cis-to-trans equilibrium (in DMSO). Thus, an enthalpy/entropy compensation effect seems to be at play for the considered conformational equilibrium.

Different methods have been proposed to measure the rate constants and the activation energy for the cis/trans isomerization. ${ }^{5,59}$ However, considering the unequal population between the two exchanging species, as well as similar spinlattice relaxation time $T_{1}$ of the two species $\left(T_{1 \text { cis }}=2.39 \mathrm{~s} ; T_{1 \text { trans }}\right.$ $=2.46 \mathrm{~s}$ ) we found the approach outlined by Perrin and Dwyer to be convenient. ${ }^{60} 2 \mathrm{D}$ exchange spectroscopy (EXSY), which provides a map of the exchanging species, was used. This approach allows for the calculation of the rate constants for a chemical exchange process by measuring the cross-peak to diagonal peak intensity ratio. The ratio of the rate constants, obtained with the optimal mixing time found $\left(\tau_{\mathrm{m}}=0.03 \mathrm{~s}\right)$, was $K_{\text {trans/cis }}=k_{c \rightarrow t} / k_{t \rightarrow c}=0.31$. This value is fully consistent with that obtained from the $\mathrm{H} \alpha$ peak integral ratio at $25^{\circ} \mathrm{C}$ (see above). From the rate constants, we can also calculate the free energy of activation for the cis to trans and the trans to cis isomerization according to the absolute rate theory. The estimated values were $\Delta G^{\ddagger}{ }_{\mathrm{c} \rightarrow \mathrm{t}}=16.4 \mathrm{kcal} / \mathrm{mol}$ and $\Delta G_{\mathrm{t} \rightarrow \mathrm{c}}^{\ddagger}=15.7 \mathrm{kcal} / \mathrm{mol}$, which lie in the lower range of observed cis/trans barriers for $N, N$ disubstituted acetamides. ${ }^{61}$ NMR spectra of 1 acquired in $\mathrm{CD}_{2} \mathrm{Cl}_{2}$ to the lower temperature of $-60{ }^{\circ} \mathrm{C}$ did not influence at all the conformational equilibrium.

A well-recognized factor, which favors the trans conformer over the cis conformer in proline analogues, is the $\mathrm{n} \rightarrow \pi^{*}$ interaction between adjacent carbonyl groups. ${ }^{20,23}$ The nature of the terminal group can affect the equilibrium, as esters are more electrophilic than amides and act as better acceptors for the $n \rightarrow \pi^{*}$ interaction. ${ }^{53}$ In our case, given the cis preference of $\mathbf{1}$, we speculated that other factors may overcome a possible $n \rightarrow \pi^{*}$ interaction. Therefore, we expected that the presence of a tertiary amide as the acceptor group would not dramatically change the conformational preference. For that reason, we decided to synthesize compound $\mathbf{2}$ as model to confirm the preference of the cis conformer in an $(S)$-indoline-2-carboxylic acid derivative involved in a peptide bond (Scheme 1). Compound 2 is short enough to be a convenient model to investigate the impact of a tertiary amide in the backbone, avoiding the occurrence of cooperative effects which would show up in larger oligomers.

The NMR analysis in DMSO- $d_{6}$ of the dimer Ac- $(2 S)$-Ind(2S)-Ind-OMe (2) demonstrated for both amidic bonds a strong preference for the cis conformation, confirming this tendency also when a tertiary amide moiety is present as terminal substituent. In Figure 3, it is possible to appreciate the influence of solvent polarity in $\mathrm{CDCl}_{3}$ and DMSO- $d_{6}$, while a complete attribution of NMR signals of the predominant cis-cis conformer of 2 in DMSO- $d_{6}$ is reported in the Experimental Section. Although compound $\mathbf{2}$ is too short to fold into a stable secondary structure, we expect the same preference for the cis geometry of the amide junction to be retained in longer oligomers of indoline-2-carboxylic acid, which will be the subject of future studies.

To investigate the cis/trans isomerization from a different perspective, a computational study was performed to determine the relative stability of the two isomers of $\mathbf{1}$ in various solvents. 


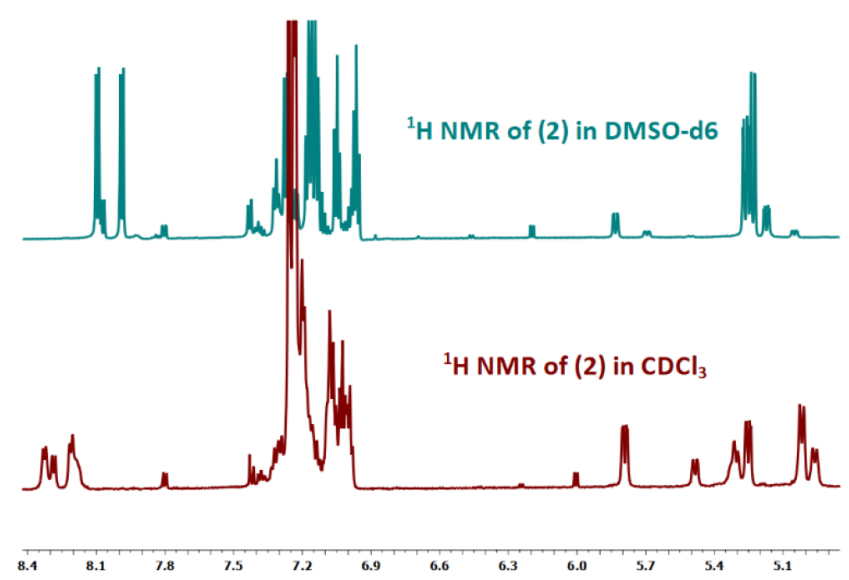

Figure 3. ${ }^{1} \mathrm{H}$ NMR of 2 in the $\mathrm{H} \alpha$ region and in the aromatic region in $\mathrm{CDCl}_{3}$ and DMSO- $d_{6}$.

Four different conformations (called C1, C2 and T1, T2, respectively) were considered, characterized by values of the $\omega$ dihedral of approximately 0 and $180 \mathrm{deg}$ ( $\mathrm{C}$ and $\mathrm{T}$ isomers ), and of the $\psi$ dihedral around +160 and -20 degrees ( 1 and 2 conformers), respectively. The optimized geometries of the $\mathrm{C} 1$, $\mathrm{C} 2$ and T1, T2 conformers in DMSO are reported in Figure 4.
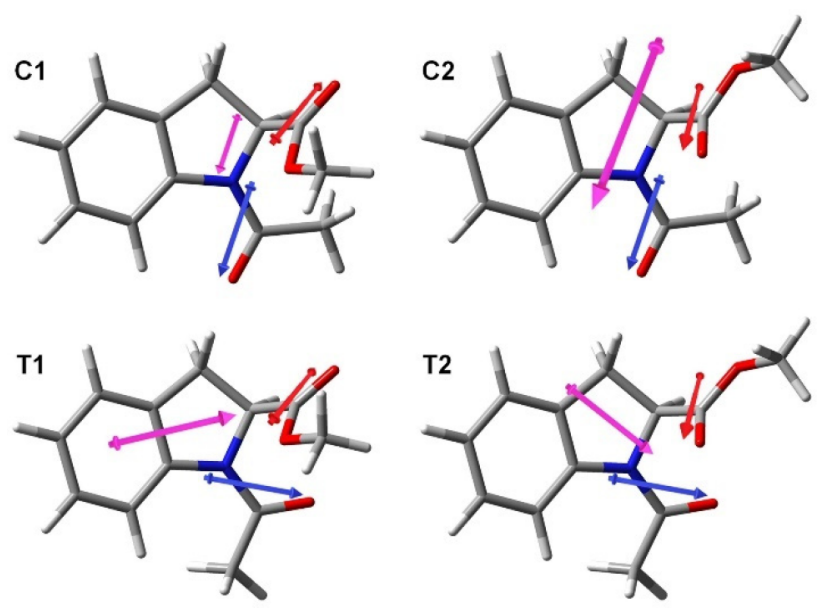

Figure 4. Optimized geometries of the four conformers of 1 in DMSO obtained using the B3LYP-D3BJ functional and the 6-311+G(d,p) basis set and the IEFPCM continuum solvation model. Arrows represent dipole moments: magenta, overall molecular dipole moment (the size is proportional to the magnitude); blue and red, local dipole moments associated to the amide and ester moiety, respectively, estimated at the same level of calculation on $\mathrm{N}, \mathrm{N}$-dimethylacetamide and methyl acetate.

For each starting geometry, a full optimization was performed, followed by a frequency calculation to characterize the optimized geometries as minima and compute, for each conformer, its Gibbs free energy. The computed Gibbs free energy differences between the various conformers in different solvents are reported in Table 3, while all of the optimized geometries and absolute Gibbs free energies are reported in the SI.

We note that, qualitatively, DFT calculations nicely reflect the experimental finding that the cis isomer is favored in all solvents, and there is a tendency toward the stabilization of the cis isomer in more polar solvents. Quantitatively, however, the impact on the conformational equilibrium of the different solvents is
Table 3. Computed Relative Free Energies of the Four Conformers of Ac-(2S)-Ind-OMe, in $\mathrm{kcal} / \mathrm{mol}$

\begin{tabular}{lllllc} 
solvent & $\mathrm{C} 1$ & $\mathrm{C} 2$ & $\mathrm{~T} 1$ & $\mathrm{~T} 2$ & $K_{\text {trans/cis }}$ \\
\hline benzene & 0.0 & 0.1 & 0.4 & 0.4 & 0.55 \\
$\mathrm{CHCl}_{3}$ & 0.0 & 0.0 & 0.4 & 0.3 & 0.52 \\
$\mathrm{CH}_{2} \mathrm{Cl}_{2}$ & 0.1 & 0.0 & 0.5 & 0.4 & 0.53 \\
$\mathrm{CH}_{3} \mathrm{OH}$ & 0.3 & 0.0 & 0.6 & 0.5 & 0.48 \\
$\mathrm{CH}_{3} \mathrm{CN}$ & 0.3 & 0.0 & 0.6 & 0.5 & 0.48 \\
$\mathrm{DMSO}$ & 0.3 & 0.0 & 0.6 & 0.5 & 0.48 \\
\hline
\end{tabular}

underestimated by calculations. From the computed dipole moments in various solvents of the cis and trans isomers, calculated as the Boltzmann average of the dipoles of the two conformers for each isomer, it appears that there is no definite prevalence of either isomer as the more polar one. This is due to the combination of the local dipoles allied with the amide and ester moieties, which in the four isomers arrange in different ways as depicted in Figure 4, yielding an overall dipole with variable direction and intensity. It is clear that, being the populations of the four conformers all very similar, and the respective dipole moments very variable, subtle changes in the populations may affect the average dipole moment substantially. This may be the reason why polarizable continuum solvent models seem not fully adequate to quantitatively describe the solvent-dependent conformational equilibrium of Ac- $(2 S)$-IndOMe (1).

For the sake of completeness, we carried out geometry optimizations in various solvents also on compound $\mathbf{2}$ (see the SI). In the dimer, angles $\omega 1, \omega 2, \psi 1$, and $\psi 2$ (Scheme 1) are allowed to vary, yielding 16 potential conformers of which 15 corresponded to stable minima. In this case, too, we found the cis-cis conformers (i.e., with $\omega 1$ and $\omega 2 \approx 0^{\circ}$ ) to be the most stable ones, in good agreement with the experimental data.

In the attempt to rationalize the observed behavior of $(S)$ indoline-2-carboxylic acid derivatives, we estimated all of the possible interactions that could influence their conformational preferences by using natural bond orbital (NBO) analysis. We first verified the extent of the $n \rightarrow \pi^{*}$ interaction for compound $\mathbf{1}$, in comparison with Ac-Pro-OMe which prefers the amide trans conformation. ${ }^{17}$ All the typical geometrical indicators of the $\mathrm{n} \rightarrow$ $\pi^{*}$ interaction $(\mathrm{C}=\mathrm{O} \cdot$. COO distance, $\mathrm{C}=\mathrm{O}-\mathrm{C}$ Bürgi-Dunitz trajectory, pyramidalization of ester $\mathrm{C}),{ }^{20}$ as well as the overlap between the $\mathrm{n}_{\mathrm{C}=\mathrm{O}}$ and $\pi^{*}$ COO orbitals, were similar for the two compounds in their trans conformations (see the SI). This finding suggested that the different conformational behavior is not related to a different extent of the $n \rightarrow \pi^{*}$ interaction. In fact, the main geometrical difference between Ac-(2S)-Ind-OMe (1) and Ac-Pro-OMe is not in the reciprocal arrangement between the amide and ester groups but in the fact that in the former compound the $\mathrm{N}$-acetyl moiety lies in the same plane as the phenyl ring, as shown in Figure 5. A possible reason for the higher stability of the cis isomer of Ac-(2S)-Ind-OMe (1) is a subtle combination between steric and electrostatic effects involving the $\mathrm{N}$-acetyl moiety. In the trans isomer of Ac- $(2 S)$ Ind-OMe, a steric repulsion between $\mathrm{CH}_{3}$ and $\mathrm{H}_{\mathrm{Ar} 4}$ is detectable, which is relieved both in the cis isomer (between $\mathrm{CH}_{3}$ and $\mathrm{CH} \alpha$ ) and in Ac-Pro-OMe (between $\mathrm{CH}_{3}$ and $\mathrm{CH}_{2} \delta$ ). Conversely, the cis isomer allows for a stabilizing attraction between $\mathrm{C}=\mathrm{O}$ and $\mathrm{H}_{\mathrm{Ar} 4}$, although this latter effect is less important than anticipated. Atom charges calculated with natural population analysis reveal a slight increase of $\mathrm{H}_{\mathrm{Ar} 4}$ charge (by $10 \%$ in $\mathrm{CHCl}_{3}$ ) passing from the trans to the cis isomer of Ac-(2S)-Ind-OMe, which might be 


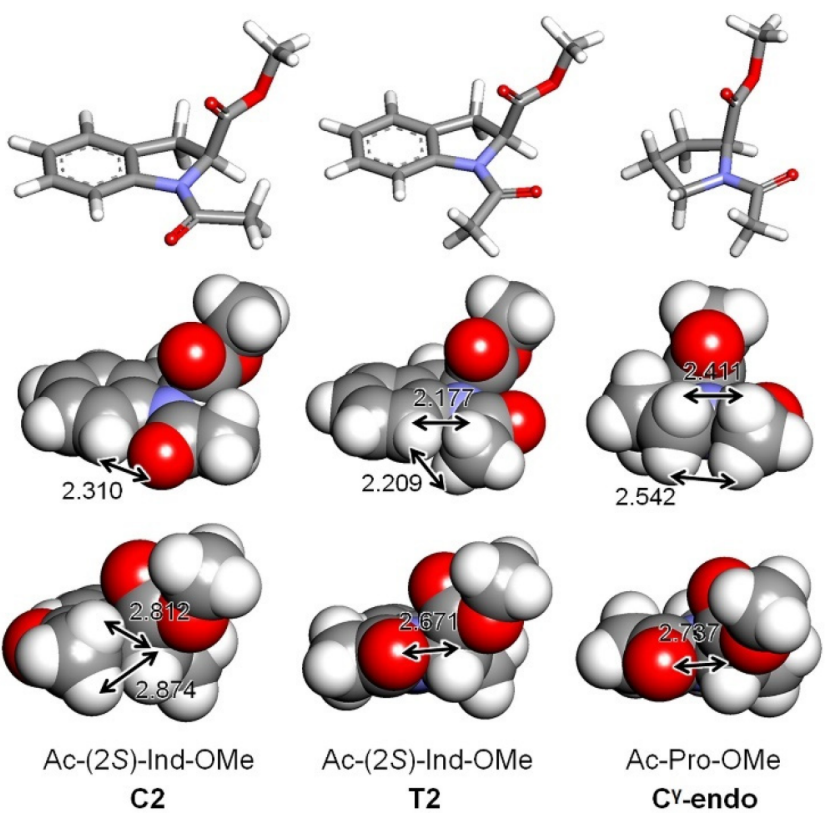

Figure 5. Analysis of selected van der Waals contacts (in $\AA$ ) for structures optimized at B3LYP-D3BJ/6-311+G(d)/IEFPCM (DMSO) level of calculation, seen from two viewpoints. Conformers $\mathrm{C} 2$ and T2 of Ac-(2S)-Ind-OMe (1) were considered for better comparison with the lowest-energy conformer of Ac-Pro-OMe.

indicative of a $\mathrm{C}-\mathrm{H}_{\mathrm{Ar} 4} \cdot \cdot \mathrm{O}=\mathrm{C}$ interaction in the cis isomer. At the same time, however, the atom charge on $\mathrm{C}=\mathrm{O}$ oxygen is the same (within $0.5 \%$ in $\mathrm{CHCl}_{3}$ ) for the two isomers. Moreover, atom charges are only slightly affected when switching from $\mathrm{CHCl}_{3}$ to DMSO; for example, the $\mathrm{C}=\mathrm{O}$ oxygen negative charge increases by $\sim 2 \%$ (absolute value) in the more polar solvent, while the $\mathrm{H}_{\mathrm{Ar} 4}$ charge increases by $\sim 1 \%$. So, although the calculations hint at a possible $\mathrm{C}-\mathrm{H} \cdot \mathrm{O}=\mathrm{C}$ interaction, we must conclude that they do not highlight a clear solvent dependence for this interaction.

\section{CONCLUSIONS}

The collected experimental and computational evidence unambiguously demonstrated that $(S)$-indoline-2-carboxylic acid derivatives, when involved in amide bonds, have a strong preference for the cis conformation, especially in polar solvents. It is interesting to note how these results confirm the findings of Siebler et al. ${ }^{53}$ on the importance of dipole moment for proline derivatives isomerization, although in our case the effect of the polarity of the solvent is much more pronounced. Besides the influence of the dipole moment on the conformational equilibrium, a combination of steric and electrostatic interactions may contribute to stabilizing the amide cis geometry. Considering that small differences at a molecular level transpose to big changes of macroscopic properties, these findings could lead to the synthesis of longer oligomers forming stable polyproline I like structures, or the use in peptide sequences of $(S)$-indoline-2-carboxylic acid as a preferential scaffold to form $\beta$-hairpins, or as a conformational constrain for the design of new organo-catalysts.

\section{EXPERIMENTAL SECTION}

General Information and Materials. All nonaqueous reactions were run in oven-dried glassware under a positive pressure of argon, with exclusion of moisture from reagents and glassware, transferring solvents and liquid reagents with hypodermic syringes. The glassware has been dried with a heating gun under vacuum and allowed to cool under argon. Anhydrous solvents and liquid reagents were obtained using standard drying techniques. Solid reagents were of commercially available grade, used without further purification and, when necessary, stored in a controlled atmosphere and/or at $-20{ }^{\circ} \mathrm{C}$. (S)-Indoline-2carboxylic acid was purchased from abcr $\mathrm{GmbH}$. Reactions were monitored by thin-layer chromatography using Merck silica gel 60 F254 plates. Visualization of the developed chromatogram was performed by UV absorbance, aqueous potassium permanganate, or iodine. Flash chromatography was performed using Sigma-Aldrich silica gel 60, particle size $40-63 \mu \mathrm{m}$, with the indicated solvent system. NMR spectra, unless otherwise specified, were recorded on Bruker Avance DRx 400, $401.36 \mathrm{MHz}$ for ${ }^{1} \mathrm{H}$ and $100.92 \mathrm{MHz}$ for ${ }^{13} \mathrm{C}$. Chemical shifts are reported in ppm with the deuterated solvent signal as the internal standard. Data are reported as follows: chemical shift, integration, multiplicity $(\mathrm{s}=$ singlet, $\mathrm{d}=$ doublet, $\mathrm{t}=$ triplet, $\mathrm{q}=$ quartet, $\mathrm{qn}=$ quintet, $\mathrm{m}=$ multiplet and $\mathrm{br}=$ broad), and coupling constant in hertz. All ${ }^{13} \mathrm{C}$ spectra were obtained with complete proton decoupling. Structural assignments were made with additional information from gCOSY, gHSQC, gHMBC, and NOESY experiments. 2D-EXSY (exchange spectroscopy) experiments, based on 2D-ROESY (rotating-frame Overhauser enhancement spectroscopy) sequence, and NOESY experiments were recorded on a VARIAN INOVA $600 \mathrm{MHz}$ instrument. The optimized 2D map was recorded by using a relaxation time of $15 \mathrm{~s}$, a mixing time of $0.03 \mathrm{~s}$; 128 increments of 4 transients of $2 \mathrm{~K}$ points each were collected. HPLC-ESI-Q/ToF flow injection analyses (FIA) were carried out with a 1200 Infinity HPLC (Agilent Technologies, USA), coupled with a quadrupole-time-of-flight tandem mass spectrometer (6530 Infinity Q-TOF; Agilent Technologies) through a Jet Stream ESI interface (Agilent). Mass Hunter Workstation Software (B.04.00) was used to control the HPLC and the mass spectrometer, for data acquisition, and for data analysis.

Methyl (S)-1-Acetylindoline-2-carboxylate Ac-(2S)-Ind-OMe (1). (S)-Indoline-2-carboxylic acid (H-Ind-OH) (2.8 g, $17.2 \mathrm{mmol})$ was dissolved in $280 \mathrm{~mL}$ of methanol and cooled to $0{ }^{\circ} \mathrm{C}$ with an ice bath. To this suspension was added dropwise thionyl chloride (1.87 $\mathrm{mL}, 25.7 \mathrm{mmol}, 1.5$ equiv). The reaction mixture was stirred for $1 \mathrm{~h}$ and allowed to reach room temperature. Afterward, the resulting solution was heated at $70{ }^{\circ} \mathrm{C}$ and allowed to stir at reflux for $16 \mathrm{~h}$. After being cooled at room temperature, the reaction mixture was concentrated under reduced pressure. The residue was dissolved in ethyl acetate (EtOAc) and washed with an aqueous saturated solution of sodium bicarbonate $\left(\mathrm{NaHCO}_{3}\right)$ three times. The combined organic layers were washed with brine, dried over $\mathrm{Na}_{2} \mathrm{SO}_{4}$, and concentrated under reduced pressure. The resulting crude material was purified by flash chromatography on silica gel using 10 to $50 \%$ EtOAc in hexane to give the desired product $(\mathrm{H}-(2 S)$-Ind-OMe $)$ as a white solid in an $82 \%$ yield $(2.5 \mathrm{~g}, 14.1 \mathrm{mmol}){ }^{1} \mathrm{H}$ NMR $\left(400 \mathrm{MHz}, \mathrm{CDCl}_{3}\right) \delta=7.12-6.99$ $(\mathrm{m}, 2 \mathrm{H}), 6.79-6.68(\mathrm{~m}, 2 \mathrm{H}), 4.39(\mathrm{dd}, J=10.2,5.5 \mathrm{~Hz}, 2 \mathrm{H}), 3.76(\mathrm{~s}$, $3 \mathrm{H}), 3.36(\mathrm{~m}, 2 \mathrm{H})$.

In a round-bottom flask, $510 \mathrm{mg}(2.9 \mathrm{mmol}, 1$ equiv) of $\mathrm{H}$-(2S)-IndOMe was dissolved in $25 \mathrm{~mL}$ of dry dichloromethane and the resulting solution stirred at $0{ }^{\circ} \mathrm{C}$. A catalytic amount $(0.5 \%)$ of 4 dimethylaminopyridine (DMAP) and $1.60 \mathrm{~mL}$ (11.5 mmol, 4 equiv) of triethylamine (TEA) were added to the solution. Acetic anhydride $(2.2 \mathrm{~mL}, 23 \mathrm{mmol}, 8$ equiv) was then added dropwise, and after $15 \mathrm{~min}$, the reaction mixture was warmed at room temperature and let stirring for $16 \mathrm{~h}$. The reaction mixture was then concentrated under reduced pressure, and the residue was dissolved in dichloromethane, acidified with $\mathrm{HCl} 1 \mathrm{M}$, and washed three times with dichloromethane. The combined organic layer layers were dried over $\mathrm{Na}_{2} \mathrm{SO}_{4}$, filtered, and concentrated under reduced pressure. The resulting crude product was purified by flash chromatography on silica gel using 10 to $50 \%$ EtOAc in hexane to give the desired product as a white solid in an $85 \%$ yield (538 $\mathrm{mg}, 2.45 \mathrm{mmol})$. TLC $R_{f}: 0.6(\mathrm{Hex} / \mathrm{EtOAc}=7: 3), \mathrm{Mp}: 65^{\circ} \mathrm{C} .{ }^{1} \mathrm{H}$ NMR $\left(400 \mathrm{MHz}, \mathrm{CDCl}_{3}\right) \delta=8.21\left(\mathrm{~d}, J=8.1 \mathrm{~Hz}, 1 \mathrm{H}_{\text {cis }}\right), 7.28-7.12\left(\mathrm{~m}, 2 \mathrm{H}_{\text {cis }}\right.$ $\left.+3 \mathrm{H}_{\text {trans }}\right), 7.03\left(\mathrm{t}, J=7.7 \mathrm{~Hz}, 1 \mathrm{H}_{\text {cis }}+1 \mathrm{H}_{\text {trans }}\right), 5.17(\mathrm{~d}, J=10.7 \mathrm{~Hz}$, $\left.1 \mathrm{H}_{\text {trans }}\right), 4.91\left(\mathrm{~d}, J=10.7 \mathrm{~Hz}, 1 \mathrm{H}_{\mathrm{cis}}\right), 3.77\left(\mathrm{~s}, 3 \mathrm{H}_{\mathrm{cis}}\right), 3.73\left(\mathrm{~s}, 3 \mathrm{H}_{\text {trans }}\right)$, $3.62\left(\mathrm{dd}, J=16.6, J=10.7 \mathrm{~Hz}, 1 \mathrm{H}_{\mathrm{cis}}\right), 3.47(\mathrm{dd}, J=16.6 \mathrm{~Hz}, J=10.7 \mathrm{~Hz}$, 
$\left.1 \mathrm{H}_{\text {trans }}\right), 3.27\left(\mathrm{~d}, J=16.6 \mathrm{~Hz}, 1 \mathrm{H}_{\mathrm{cis}}\right), 3.10\left(\mathrm{~d}, J=16.6 \mathrm{~Hz}, 1 \mathrm{H}_{\text {trans }}\right), 2.48$ $\left(\mathrm{s}, 3 \mathrm{H}_{\text {trans }}\right), 2.17\left(\mathrm{~s}, 3 \mathrm{H}_{\text {cis }}\right) .{ }^{13} \mathrm{C}\left\{{ }^{1} \mathrm{H}\right\} \mathrm{NMR}\left(100 \mathrm{MHz}, \mathrm{CDCl}_{3}\right) \delta: 171.8$, $168.9,142.6,130.9,128.4,128.0,127.9,125.7,124.2,124.0,123.5$, 117.4, 113.8, 61.4, 60.6, 53.0, 52.5, 33.6, 31.5, 29.7, 24.5, 23.7. HRMS (TOF MS ES+): $\mathrm{m} / z[\mathrm{M}+\mathrm{Na}]^{+}$calcd for $\mathrm{C}_{12} \mathrm{H}_{13} \mathrm{NO}_{3} 242.0788$; found 242.0784. Analytical HPLC purity $97 \%$.

Methyl (S)-1-((S)-1-Acetylindoline-2-carbonyl)indoline-2carboxylate, Ac- $((2 S)-\text { Ind })_{2}-\mathrm{OMe}$ (2). In a round-bottom flask, $(S)$-indoline-2-carboxylic acid (H-(2S)-Ind-OH) $(0.6 \mathrm{~g}, 3.6 \mathrm{mmol}, 1$ equiv) was dissolved in $25 \mathrm{~mL}$ of dry dichloromethane and allowed to stir and cool in an ice bath. Triethylamine (TEA) $(2.0 \mathrm{~mL}, 14.4 \mathrm{mmol}, 4$ equiv) and a catalytic amount (0.5\%) of DMAP were added. To this solution, $2.7 \mathrm{~mL}$ of acetic anhydride $(28.8 \mathrm{mmol}, 8$ equiv) was then added dropwise. The reaction mixture was warmed at room temperature and stirred for $16 \mathrm{~h}$. The resulting mixture was then concentrated under reduced pressure, and the residue was dissolved in dichloromethane, acidified with $\mathrm{HCl} 1 \mathrm{M}$, and washed three times with dichloromethane. The combined organic layer layers were dried over $\mathrm{Na}_{2} \mathrm{SO}_{4}$, filtered, and concentrated under reduced pressure. The product Ac-(2S)-Ind-OH was obtained as a white solid with a yield of $85 \%(0.63 \mathrm{~g})$ and used without further purification. ${ }^{1} \mathrm{H}$ NMR (400 $\left.\mathrm{MHz}, \mathrm{DMSO}-d_{6}\right) \delta=8.20(\mathrm{~d}, J=8.0 \mathrm{~Hz}, 0.75 \mathrm{H}), 7.30-6.95(\mathrm{~m}$, $3.25 \mathrm{H}), 5.21(\mathrm{~d}, J=9.0 \mathrm{~Hz}, 0.75 \mathrm{H})$ and $4.87(\mathrm{~d}, J=9.0 \mathrm{~Hz}, 0.25 \mathrm{H})$, $3.67-3.20(\mathrm{~m}, 2 \mathrm{H}), 2.52(\mathrm{~s}, 2.25 \mathrm{H})$ and $2.19(\mathrm{~s}, 0.75 \mathrm{H})$.

In a two-neck round-bottom flask, $210 \mathrm{mg}(1.02 \mathrm{mmol}, 1$ equiv) of Ac-(2S)-Ind-OH was dissolved in dry dichloromethane under argon. The coupling reagent 2-chloro-1-methylpyridinium iodide (Mukaiyama's reagent) ( $365 \mathrm{mg}, 1.43 \mathrm{mmol}, 1.4$ equiv) and freshly distilled TEA $(0.4 \mathrm{~mL}, 2.86 \mathrm{mmol}, 2.8$ equiv) were added into the solution. The amine $\mathrm{H}$-(2S)-Ind-OMe (181 mg, $1.02 \mathrm{mmol}, 1$ equiv) was added, and the reaction mixture was heated at reflux for $16 \mathrm{~h}$ before being allowed to cool to room temperature. The reaction mixture was then diluted with DCM and washed with $\mathrm{HCl} 1 \mathrm{M}$, aqueous saturated sodium bicarbonate, and brine. The organic layer was then dried over $\mathrm{Na}_{2} \mathrm{SO}_{4}$ and evaporated under reduced pressure. The resulting solid was purified by flash chromatography on silica gel using $10-50 \%$ EtOAc in hexane. The desired product was obtained as white solid in an isolated yield of $46 \%$ for solubility issues $(168 \mathrm{mg}, 0.46 \mathrm{mmol})$. TLC Rf $=0.6$ (DCM:MeOH = 9:1), M.P. $=175{ }^{\circ} \mathrm{C}(\mathrm{dec})^{1} \mathrm{H}$ NMR $(400 \mathrm{MHz}$, $\left.\mathrm{CDCl}_{3}\right) \delta=8.35-8.14(\mathrm{~m}, 1 \mathrm{H}), 7.36-7.11(\mathrm{~m}, 5 \mathrm{H}), 7.11-6.95(\mathrm{~m}$, $2 \mathrm{H}$ ), 5.87-5.75, 5.51-5.45, 5.34-5.21 and 5.12-4.92 (four $\mathrm{m}, 2 \mathrm{H}$ ), 3.95-3.00 (m, 7H), 2.47 and 2.18 (couple of d, 3H). ${ }^{1} \mathrm{H}$ NMR characterization of prevailing cis-cis species $(>70 \%)$ in the stereoisomers mixture in DMSO- $d_{6}$ on a $600 \mathrm{MHz}$ is reported in the SI. ${ }^{13} \mathrm{C}\left\{{ }^{1} \mathrm{H}\right\}$ NMR (150 MHz, DMSO- $\left.d_{6}\right) \delta=171.7,169.7,169.2,143.5$, 142.2 , 129.5, 128.9, 127.4, 127.2, 124.7, 124.3, 123.1, 116.0, 115.9, $115.8,113.8,61.2,61.0,60.0,59.7,59.6,53.1,52.1,33.4,33.0,32.9$, 30.5, 23.6, 23.5, 20.7, 14.1. HRMS (TOF MS ES+): $m / z[\mathrm{M}+\mathrm{Na}]^{+}$ calcd for $\mathrm{C}_{12} \mathrm{H}_{20} \mathrm{~N}_{2} \mathrm{O}_{4}$ 387.1315; found 387.1317. Analytical HPLC purity $98 \%$.

Comment over the Stability of Indoline-2-carboxylic Acid Derivatives. The starting material $(S)$-indoline-2-carboxylic acid $(\mathrm{H}-$ $(2 S)-I n d-O H)$ has been purchased by abcr $\mathrm{GmBh}$ with a declared purity up to $95 \%$. In our opinion, the risk of degradation of the carboxylic moiety is low, but on the other hand, the risk of oxidation to form $1 H$-indole-2-carboxylic acid could have been higher, and we checked regularly, over a long period of time (more than one year), the purity of the SM and of the synthesized derivatives by ${ }^{1} \mathrm{H}$ NMR. We could observe that if the SM and $\mathrm{H}$-Ind-OMe were not correctly stored under argon at $0{ }^{\circ} \mathrm{C}$ they could change color to a reddish powder and show the formation of a small signal on the ${ }^{1} \mathrm{H}$ NMR typical of the indole. However, we were pleased to notice then whenever the secondary amine was protected as an acetamide or involved in a peptide bond, compounds remain stable and pure even after 2 years.

Assignment of ${ }^{1} \mathrm{H}$ NMR Signals of 1. Cis and trans stereoisomers of $\mathbf{1}$ were attributed on the basis of NOESY analysis (see the SI). Even though the majority of dipolar interactions suffered from exchange processes occurring between the two species, one effect was selective for the trans one. In particular, in $\mathrm{CDCl}_{3} \mathrm{H} \alpha$ at $5.17 \mathrm{ppm}$ produced $\mathrm{NOE}$ at $2.17 \mathrm{ppm}$ (acetyl group), which is due to exchange processes, but not at
$2.48 \mathrm{ppm}$, which is its acetyl group. On the contrary, $\mathrm{H} \alpha$ at $4.91 \mathrm{ppm}$ gave NOEs at both frequencies of acetyl groups. Therefore, $\mathrm{H} \alpha$ centered at 5.17 and $4.91 \mathrm{ppm}$ must be attributed to trans and cis isomer, respectively. Starting from the frequency of $\mathrm{H} \alpha$ and based on the analysis of scalar correlations and integration, the complete assignment of cis and trans isomer was obtained (see the SI).

Optimization of the Mixing Time for EXSY Experiments. The rate constants and the activation energy for the cis/trans isomerization were determined in DMSO- $d_{6}$ from $2 \mathrm{D}$ exchange spectroscopy (EXSY) which provides a map of the exchanging species. Considering the greatly unequal populations of the two exchanging species, as well as similar spin-lattice relaxation time $T_{1}$ of the two species $\left(T_{1 c i s}=2.39 \mathrm{~s}\right.$; $T_{1 \text { trans }}=2.46 \mathrm{~s}$ ) we found the approach outlined by Perrin and Dwyer convenient. This approach allows for calculation of rate constant for chemical exchange by knowing the diagonal peak to cross-peak intensity ratio. For a simple two-site exchange, the total exchange rate $k$ $\left(k=k_{t \rightarrow c}+k_{c \rightarrow t}\right)$ is given by the equation

$$
k=\frac{1}{\tau_{m}} \ln \frac{r+1}{r-1}
$$

The term $r$ accounts for unequal populations and is defined as

$$
r=4 X_{C} X_{T} \frac{I_{C C}+I_{T T}}{I_{C T}+I_{T C}}-\left(X_{C}-X_{T}\right)^{2}
$$

where $I_{C C}$ and $I_{T T}$ are the diagonal peak intensities of two exchangeable resonances in the EXSY, $I_{T C}$ and $I_{C T}$ are the intensities of the exchange cross peaks, and $\tau_{m}$ is the mixing time. $X_{C}$ and $X_{T}$ are the mole fractions of the cis and trans forms. The choice of the mixing time $\tau_{m}$ is critical. Kinetic effects on the cross-peak intensities will be too small to measure accurately, if it is too short. However, the effects will be so large as to be insensitive to the kinetic parameters, if it is too long. The optimum mixing time should be chosen to minimize the error in the rate constant and an approximate expression was shown to be

$$
\tau_{\mathrm{m}, \mathrm{opt}} \sim \frac{1}{T_{1}^{-1}+k_{t \rightarrow c}+k_{c \rightarrow t}}
$$

We found that $\tau_{\mathrm{m}}=0.03 \mathrm{~s}$ is the closest to the optimal value.

${ }^{1} \mathrm{H}$ NMR Characterization of Prevailing Cis-Cis Species $(>70 \%)$ of 2 in DMSO- $d_{6}$ on a $600 \mathrm{MHz}$ Instrument. The main species of Ac-Ind-Ind-OMe (2) in DMSO- $d_{6}$ was fully characterized by compared analysis of homonuclear and heteronuclear scalar correlations in COSY and HSQC maps and homonuclear dipolar correlations in ROESY map (see the SI). The prevailing conformer was identified as the cis-cis one on the basis of the significant ROE detected between the more intense singlets at 2.05 and $3.73 \mathrm{ppm}$ due to the methyl protons of the acetyl and the ester functions, respectively. Therefore, among NMR signals of $\mathrm{H} \alpha$ of the conformer mixture (5.00-6.00 ppm), the two more intense ones (doublet of doublets) at 5.24 and $5.27 \mathrm{ppm}$ were assigned to the two units of the cis-cis species. In particular, the high-frequency signal (5.27 ppm) was attributed to the $\mathrm{H} \alpha$ of the residue with the $N$ acetyl terminal substituent, which is in spatial proximity of the methyl group of acetyl moiety (ROE constraint). Accordingly, to the above said stereochemical assignment, no ROEs between aromatic protons and $\mathrm{H} \alpha$ of methyl ester terminal residue were detected. Starting from each $\mathrm{H} \alpha$, the two diastereotopic protons of their adjacent methylenes were assigned $(3.29 / 3.78 \mathrm{ppm}$ for the $N$-acetyl residue and 3.34/3.76 ppm for the methyl ester residue) by means of their scalar correlations. $\mathrm{Har}_{1}$ of each residue was identified on the basis of the ROE effects produced by the methylene protons. Resonances of aromatic protons of each residue were assigned on the basis of their scalar correlations, starting from $\mathrm{Har}_{1}$. NMR characterization data for the cis-cis species are collected in the SI.

Computational Details. Conformational analysis was run by the systematic conformational search algorithm implemented in Spartan'18 (Wavefunction, Inc., Irvine, CA, 2018) using the Merck Molecular Force Field (MMFF). Geometry optimizations were performed using density functional theory with the B3LYP exchange-correlation functional, ${ }^{62}$ augmented with Grimme's GD3 empirical dispersion correction dispersion, ${ }^{63}$ in conjunction with the $6-311+G(d)$ basis set. 
Solvation effects have been accounted for using the integral equation formalism ${ }^{64,65}$ formulation of the polarizable continuum model (IEFPCM). ${ }^{66}$ Natural bond orbital (NBO) analysis was run with NBO version $3 .{ }^{67}$ All of the DFT calculations have been performed using the Gaussian 16 suite of programs. ${ }^{68}$

HPLC Analysis of 1 and 2. A 1000 ppm solution was prepared in $\mathrm{DMSO}$ and then further diluted in $\mathrm{MeOH}$ to ca. $50 \mathrm{ppm}$ and injected in the chromatographic system. The separation was performed on an Agilent Zorbax Extend C18 Rapid resolution HT column $(50 \times 2.1$ $\mathrm{mm}, 1.8 \mu \mathrm{m}$ particle size). The injection volume was $1 \mu \mathrm{L}$, and the column temperature was $30^{\circ} \mathrm{C}$. Separation was obtained by using a gradient of $0.1 \%$ formic acid in water (eluent $\mathrm{A}$ ) and $0.1 \%$ formic acid in acetonitrile (eluent B) programmed as follows: $90 \%$ A for $2 \mathrm{~min}$, followed by a linear gradient to $50 \% \mathrm{~B}$ in $9 \mathrm{~min}$, then to $70 \% \mathrm{~B}$ in 3.3 min, finally to $90 \%$ B in $3.7 \mathrm{~min}$ held for $12 \mathrm{~min}$ at $90 \% \mathrm{~B}$. Reequilibration time for each analysis was $13 \mathrm{~min}$. The chromatographic runs were performed at a flow rate of $0.2 \mathrm{~mL} / \mathrm{min}$. The eluents were all HPLC-MS grade, Sigma-Aldrich. The MS acquisition was performed in full scan, and the Jet Stream ESI operating conditions were: drying gas $\left(\mathrm{N}_{2}\right.$, purity $\left.>98 \%\right): 350{ }^{\circ} \mathrm{C}$ at $10 \mathrm{~L} / \mathrm{min}$; capillary voltage $4.5 \mathrm{kV}$; nebulizer gas 35 psig; sheath gas $\left(\mathrm{N}_{2}\right.$, purity $\left.>98 \%\right): 375^{\circ} \mathrm{C}$ at $11 \mathrm{~L} /$ min. High-resolution mass spectra were acquired in the range 100$3200 \mathrm{~m} / z$ in high-resolution positive mode. The fragmentor was kept at $175 \mathrm{~V}$, nozzle voltage $1000 \mathrm{~V}$, skimmer $65 \mathrm{~V}$, octapole RF $750 \mathrm{~V}$. The mass axis was calibrated prior analyses using the Agilent tuning mix HP0321 (Agilent Technologies) prepared in acetonitrile and water.

\section{ASSOCIATED CONTENT}

\section{s) Supporting Information}

The Supporting Information is available free of charge at https://pubs.acs.org/doi/10.1021/acs.joc.1c00184.

Full characterization of the synthesized compounds, NMR experiments, and calculation details (PDF)

FAIR data, including the primary NMR FID files, for compounds 1 and $\mathbf{2}$ (ZIP)

\section{AUTHOR INFORMATION}

\section{Corresponding Author}

Gaetano Angelici - Dipartimento di Chimica e Chimica Industriale, Università di Pisa, 56124 Pisa, Italy; ○ orcid.org/0000-0002-4397-3449;

Email: gaetano.angelici@unipi.it

\section{Authors}

Matteo Pollastrini - Dipartimento di Chimica e Chimica Industriale, Università di Pisa, 56124 Pisa, Italy; ○ orcid.org/0000-0001-9334-2613

Filippo Lipparini - Dipartimento di Chimica e Chimica Industriale, Università di Pisa, 56124 Pisa, Italy; () orcid.org/0000-0002-4947-3912

Luca Pasquinelli - Dipartimento di Chimica e Chimica Industriale, Università di Pisa, 56124 Pisa, Italy

Federica Balzano - Dipartimento di Chimica e Chimica Industriale, Università di Pisa, 56124 Pisa, Italy; (1) orcid.org/0000-0001-6916-321X

Gloria Uccello Barretta - Dipartimento di Chimica e Chimica Industriale, Università di Pisa, 56124 Pisa, Italy

Gennaro Pescitelli - Dipartimento di Chimica e Chimica Industriale, Università di Pisa, 56124 Pisa, Italy; () orcid.org/0000-0002-0869-5076

Complete contact information is available at: https://pubs.acs.org/10.1021/acs.joc.1c00184

\section{Funding}

Financial support from the University of Pisa (PRA 2018_23 and PRA 2020_77) is gratefully acknowledged.

\section{Notes}

The authors declare no competing financial interest.

\section{ACKNOWLEDGMENTS}

G.A. acknowledges the contribution of the COST Action CA17120. G.A. is grateful to Prof. Ilaria Degano for HPLCHRMS analysis. G.P. acknowledges the CINECA award under the ISCRA initiative for the availability of high-performance computing resources and support.

\section{REFERENCES}

(1) Siebler, C.; Erdmann, R. S.; Wennemers, H. Switchable Proline Derivatives: Tuning the Conformational Stability of the Collagen Triple Helix by PH Changes. Angew. Chem., Int. Ed. 2014, 53 (39), 10340-10344.

(2) Schnitzer, T.; Wennemers, H. Influence of the Trans/Cis Conformer Ratio on the Stereoselectivity of Peptidic Catalysts. J. Am. Chem. Soc. 2017, 139 (43), 15356-15362.

(3) Erdmann, R. S.; Wennemers, H. Functionalizable Collagen Model Peptides. J. Am. Chem. Soc. 2010, 132 (40), 13957-13959.

(4) Erdmann, R. S.; Wennemers, H. Importance of Ring Puckering versus Interstrand Hydrogen Bonds for the Conformational Stability of Collagen. Angew. Chem., Int. Ed. 2011, 50 (30), 6835-6838.

(5) Erdmann, R. S.; Wennemers, H. Effect of Sterically Demanding Substituents on the Conformational Stability of the Collagen Triple Helix. J. Am. Chem. Soc. 2012, 134 (41), 17117-17124.

(6) Wilhelm, P.; Lewandowski, B.; Trapp, N.; Wennemers, H. A Crystal Structure of an Oligoproline PPII-Helix, at Last. J. Am. Chem. Soc. 2014, 136 (45), 15829-15832.

(7) Lewandowska, U.; Zajaczkowski, W.; Pisula, W.; Ma, Y.; Li, C.; Mullen, K.; Wennemers, H. Effect of Structural Modifications on the Self-Assembly of Oligoprolines Conjugated with Sterically Demanding Chromophores. Chem. - Eur. J. 2016, 22 (11), 3804-3809.

(8) Lewandowska, U.; Zajaczkowski, W.; Chen, L.; Bouillière, F.; Wang, D.; Koynov, K.; Pisula, W.; Müllen, K.; Wennemers, H. Hierarchical Supramolecular Assembly of Sterically Demanding $\pi$ Systems by Conjugation with Oligoprolines. Angew. Chem., Int. Ed. 2014, 53 (46), n/a-n/a.

(9) Gazit, E. A Possible Role for П-stacking in the Self-assembly of Amyloid Fibrils. FASEB J. 2002, 16 (1), 77-83.

(10) Tamamis, P.; Adler-Abramovich, L.; Reches, M.; Marshall, K.; Sikorski, P.; Serpell, L.; Gazit, E.; Archontis, G. Self-Assembly of Phenylalanine Oligopeptides: Insights from Experiments and Simulations. Biophys. J. 2009, 96 (12), 5020-5029.

(11) Reches, M.; Gazit, E. Formation of Closed-Cage Nanostructures by Self-Assembly of Aromatic Dipeptides. Nano Lett. 2004, 4 (4), 581585 .

(12) Gilead, S.; Gazit, E. Self-Organization of Short Peptide Fragments: From Amyloid Fibrils to Nanoscale Supramolecular Assemblies. Supramol. Chem. 2005, 17 (1-2), 87-92.

(13) Smith, A. M.; Williams, R. J.; Tang, C.; Coppo, P.; Collins, R. F.; Turner, M. L.; Saiani, A.; Ulijn, R. V. Fmoc-Diphenylalanine Self Assembles to a Hydrogel via a Novel Architecture Based on $\pi-\pi$ Interlocked $\beta$-Sheets. Adv. Mater. 2008, 20 (1), 37-41.

(14) Cherny, I.; Gazit, E. Amyloids: Not Only Pathological Agents but Also Ordered Nanomaterials. Angew. Chem., Int. Ed. 2008, 47 (22), $4062-4069$.

(15) Ulijn, R. V.; Smith, A. M. Designing Peptide Based Nanomaterials. Chem. Soc. Rev. 2008, 37 (4), 664-675.

(16) Makam, P.; Gazit, E. Minimalistic Peptide Supramolecular CoAssembly: Expanding the Conformational Space for Nanotechnology. Chem. Soc. Rev. 2018, 47 (10), 3406-3420.

(17) Hinderaker, M. P.; Raines, R. T. An Electronic Effect on Protein Structure. Protein Sci. 2003, 12 (6), 1188-1194. 
(18) Gorske, B. C.; Bastian, B. L.; Geske, G. D.; Blackwell, H. E. Local and Tunable $\overrightarrow{\mathrm{N}} \pi^{*}$ Interactions Regulate Amide Isomerism in the Peptoid Backbone. J. Am. Chem. Soc. 2007, 129 (29), 8928-8929.

(19) Shah, N. H.; Butterfoss, G. L.; Nguyen, K.; Yoo, B.; Bonneau, R.; Rabenstein, D. L.; Kirshenbaum, K. Oligo(N- Aryl Glycines): A New Twist on Structured Peptoids. J. Am. Chem. Soc. 2008, 130 (49), 16622-16632.

(20) Choudhary, A.; Gandla, D.; Krow, G. R.; Raines, R. T. Nature of Amide Carbonyl-Carbonyl Interactions in Proteins. J. Am. Chem. Soc. 2009, 131 (21), 7244-7246.

(21) Caumes, C.; Roy, O.; Faure, S.; Taillefumier, C. The Click Triazolium Peptoid Side Chain: A Strong Cis-Amide Inducer Enabling Chemical Diversity. J. Am. Chem. Soc. 2012, 134 (23), 9553-9556.

(22) Aliouat, H.; Caumes, C.; Roy, O.; Zouikri, M.; Taillefumier, C.; Faure, S. 1,2,3-Triazolium-Based Peptoid Oligomers. J. Org. Chem. 2017, 82 (5), 2386-2398.

(23) Newberry, R. W.; Raines, R. T. The $\mathrm{N} \rightarrow \pi *$ Interaction. Acc. Chem. Res. 2017, 50 (8), 1838-1846.

(24) Newberry, R. W.; Vanveller, B.; Guzei, I. A.; Raines, R. T. N $\pi^{*}$ Interactions of Amides and Thioamides: Implications for Protein Stability. J. Am. Chem. Soc. 2013, 135 (21), 7843-7846.

(25) Martinez, C. R.; Iverson, B. L. Rethinking the Term "Pi-Stacking. Chem. Sci. 2012, 3 (7), 2191-2201.

(26) Wang, J.; Liu, K.; Xing, R.; Yan, X. Peptide Self-Assembly: Thermodynamics and Kinetics. Chem. Soc. Rev. 2016, 45 (20), 55895604.

(27) Roy, O.; Caumes, C.; Esvan, Y.; Didierjean, C.; Faure, S.; Taillefumier, C. The Tert-Butyl Side Chain: A Powerful Means to Lock Peptoid Amide Bonds in the Cis Conformation. Org. Lett. 2013, 15 (9), 2246-2249.

(28) Angelici, G.; Bhattacharjee, N.; Roy, O.; Faure, S.; Didierjean, C.; Jouffret, L.; Jolibois, F.; Perrin, L.; Taillefumier, C. Weak Backbone $\mathrm{CH} \cdots \mathrm{O}=\mathrm{C}$ and Side Chain $\mathrm{TBu} \cdots \mathrm{TBu}$ London Interactions Help Promote Helix Folding of Achiral NtBu Peptoids. Chem. Commun. 2016, 52 (24), 4573-4576.

(29) Dumonteil, G.; Bhattacharjee, N.; Angelici, G.; Roy, O.; Faure, S.; Jouffret, L.; Jolibois, F.; Perrin, L.; Taillefumier, C. Exploring the Conformation of Mixed Cis- Trans $\alpha, \beta$-Oligopeptoids: A Joint Experimental and Computational Study. J. Org. Chem. 2018, 83 (12), 6382.

(30) Beausoleil, E.; L'Archeveque, B.; Belec, L.; Atfani, M.; Lubell, W. D. 5-tert-Butylproline. J. Org. Chem. 1996, 3263 (7), 9447-9454.

(31) Beausoleil, E.; Lubell, W. D. An Examination of the Steric Effects of 5-Tert-Butylproline on the Conformation of Polyproline and the Cooperative Nature of Type II to Type I Helical Interconversion. Biopolymers 2000, 53 (3), 249-256.

(32) Angelici, G.; Falini, G.; Hofmann, H. J.; Huster, D.; Monari, M.; Tomasini, C. A Fiberlike Peptide Material Stabilized by Single Intermolecular Hydrogen Bonds. Angew. Chem., Int. Ed. 2008, 47 (42), 8075-8078.

(33) Angelici, G.; Górecki, M.; Pescitelli, G.; Zanna, N.; Monari, M.; Tomasini, C. Synthesis and Structure Analysis of Ferrocene-Containing Pseudopeptides. Biopolymers 2018, 110, e23072.

(34) Castellucci, N.; Angelici, G.; Falini, G.; Monari, M.; Tomasini, C. L-Phe-D-Oxd: A Privileged Scaffold for the Formation of Supramolecular Materials. Eur. J. Org. Chem. 2011, 2011 (16), 3082-3088.

(35) Tomasini, C.; Angelici, G.; Castellucci, N. Foldamers Based on Oxazolidin-2-Ones. Eur. J. Org. Chem. 2011, 2011 (20-21), 36483669.

(36) Zanna, N.; Iaculli, D.; Tomasini, C. The Effect of L-DOPA Hydroxyl Groups on the Formation of Supramolecular Hydrogels. Org. Biomol. Chem. 2017, 15 (27), 5797-5804.

(37) Giuri, D.; Zanna, N.; Tomasini, C. Low Molecular Weight Gelators Based on Functionalized L-Dopa Promote Organogels Formation. Gels 2019, 5 (2), 27.

(38) Di Silvio, S.; Bologna, F.; Milli, L.; Giuri, D.; Zanna, N.; Castellucci, N.; Monari, M.; Calvaresi, M.; Górecki, M.; Angelici, G.; Tomasini, C.; Pescitelli, G. Elusive $\pi$-Helical Peptide Foldamers
Spotted by Chiroptical Studies. Org. Biomol. Chem. 2020, 18 (5), 865877.

(39) Ganguly, H. K.; Basu, G. Conformational Landscape of Substituted Prolines. Biophys. Rev. 2020, 12 (1), 25-39.

(40) Kubyshkin, V. Stabilization of the Triple Helix in Collagen Mimicking Peptides. Org. Biomol. Chem. 2019, 17 (35), 8031-8047.

(41) Pandey, A. K.; Naduthambi, D.; Thomas, K. M.; Zondlo, N. J. Proline Editing: A General and Practical Approach to the Synthesis of Functionally and Structurally Diverse Peptides. Analysis of Steric versus Stereoelectronic Effects of 4-Substituted Prolines on Conformation within Peptides. J. Am. Chem. Soc. 2013, 135 (11), 4333-4363.

(42) Krow, G. R.; Edupuganti, R.; Gandla, D.; Yu, F.; Sender, M.; Sonnet, P. E.; Zdilla, M. J.; Debrosse, C.; Cannon, K. C.; Ross, C. W.; Choudhary, A.; Shoulders, M. D.; Raines, R. T. Synthesis of Conformationally Constrained 5-Fluoro- and 5-Hydroxymethanopyrrolidines. Ring-Puckered Mimics of Gauche - And Anti -3-Fluoro- and 3-Hydroxypyrrolidines. J. Org. Chem. 2011, 76 (10), 3626-3634.

(43) Hodges, J. A.; Raines, R. T. Stereoelectronic Effects on Collagen Stability: The Dichotomy of 4-Fluoroproline Diastereomers. J. Am. Chem. Soc. 2003, 125 (31), 9262-9263.

(44) Keller, M.; Sager, C.; Dumy, P.; Schutkowski, M.; Fischer, G. S.; Mutter, M. Enhancing the Proline Effect: Pseudo-Prolines for Tailoring Cis/ Trans Isomerization. J. Am. Chem. Soc. 1998, 120 (12), 27142720.

(45) Kubyshkin, V.; Budisa, N. Construction of a Polyproline Structure with Hydrophobic Exterior Using Octahydroindole-2Carboxylic Acid. Org. Biomol. Chem. 2017, 15 (3), 619-627.

(46) Trabocchi, A.; Scarpi, D.; Guarna, A. Structural Diversity of Bicyclic Amino Acids. Amino Acids 2008, 34 (1), 1-24.

(47) Reimer, U.; Fischer, G. Local Structural Changes Caused by Peptidyl-Prolyl Cis/Trans Isomerization in the Native State of Proteins. Biophys. Chem. 2002, 96 (2-3), 203-212.

(48) Fischer, G.; Aumüller, T. Regulation of Peptide Bond Cis/Trans Isomerization by Enzyme Catalysis and Its Implication in Physiological Processes. Rev. Physiol. Biochem. Pharmacol. 2003, 148, 105-150.

(49) Fischer, G. Chemical Aspects of Peptide Bond Isomerisation. Chem. Soc. Rev. 2000, 29 (2), 119-127.

(50) Keller, M.; Sager, C.; Dumy, P.; Schutkowski, M.; Fischer, G. S.; Mutter, M. Enhancing the Proline Effect: Pseudo-Prolines for Tailoring Cis/ Trans Isomerization. J. Am. Chem. Soc. 1998, 120 (12), 27142720.

(51) Pappenberger, G.; Aygün, H.; Engels, J. W.; Reimer, U.; Fischer, G.; Kiefhaber, T. Nonprolyl Cis Peptide Bonds in Unfolded Proteins Cause Complex Folding Kinetics. Nat. Struct. Biol. 2001, 8 (5), 452458.

(52) Warren, J. G.; Revilla-López, G.; Alemán, C.; Jiménez, A. I.; Cativiela, C.; Torras, J. Conformational Preferences of Proline Analogues with a Fused Benzene Ring. J. Phys. Chem. B 2010, 114 (36), 11761-11770.

(53) Siebler, C.; Maryasin, B.; Kuemin, M.; Erdmann, R. S.; Rigling, C.; Grünenfelder, C.; Ochsenfeld, C.; Wennemers, H. Importance of Dipole Moments and Ambient Polarity for the Conformation of XaaPro Moieties - a Combined Experimental and Theoretical Study. Chem. Sci. 2015, 6 (12), 6725-6730.

(54) Reichardt, C.; Welton, T. Solvents and Solvent Effects in Organic Chemistry, 4th ed.; Wiley-VCH: Weinheim, 2011.

(55) Zefirov, N. S.; Samoshin, V. V. Parabolic Relationship between Free Energies of Comformational and Isomerizational Equilibria and the Polarity of Solvents. Tetrahedron Lett. 1981, 22 (23), 2209-2212.

(56) Berger, G.; Chab-Majdalani, I.; Hanessian, S. Properties of the Amide Bond Involving Proline 4,5-Methanologues: An Experimental and Theoretical Study. Isr. J. Chem. 2017, 57 (3), 292-302.

(57) Troganis, A.; Gerothanassis, I. P.; Athanassiou, Z.; Mavromoustakos, T.; Hawkes, G. E.; Sakarellos, C. Thermodynamic Origin of Cis/Trans Isomers of a Proline-Containing $\beta$-Turn Model Dipeptide in Aqueous Solution: A Combined Variable Temperature 1H-Nmr, Two-Dimensional 1H, $1 \mathrm{H}$ Gradient Enhanced Nuclear Overhauser Effect Spectroscopy (NOESY), One-Dimensional. Biopolymers 2000, $53(1), 72-83$. 
(58) Eberhardt, E. S.; Panasik, N.; Raines, R. T. Inductive Effects on the Energetics of Prolyl Peptide Bond Isomerization: Implications for Collagen Folding and Stability. J. Am. Chem. Soc. 1996, 118 (49), 12261-12266.

(59) Renner, C. Fluoroprolines as Tools for Protein Design and Engineering. Angew. Chem., Int. Ed. 2001, 40 (5), 923-925.

(60) Perrin, C. L.; Dwyer, T. J. Application of Two-Dimensional NMR to Kinetics of Chemical Exchange. Chem. Rev. 1990, 90 (6), 935-967.

(61) Stewart, W. E.; Siddall, T. H. Nuclear Magnetic Resonance Studies of Amides. Chem. Rev. 1970, 70 (5), 517-551.

(62) Becke, A. D. Density-Functional Thermochemistry. III. The Role of Exact Exchange. J. Chem. Phys. 1993, 98 (7), 5648-5652.

(63) Grimme, S.; Ehrlich, S.; Goerigk, L. Effect of the Damping Function in Dispersion Corrected Density Functional Theory. J. Comput. Chem. 2011, 32 (7), 1456-1465.

(64) Cancès, E.; Mennucci, B.; Tomasi, J. A New Integral Equation Formalism for the Polarizable Continuum Model: Theoretical Background and Applications to Isotropic and Anisotropic Dielectrics. J. Chem. Phys. 1997, 107 (8), 3032-3041.

(65) Lipparini, F.; Scalmani, G.; Mennucci, B.; Cancès, E.; Caricato, M.; Frisch, M. J. A Variational Formulation of the Polarizable Continuum Model. J. Chem. Phys. 2010, 133 (1), 014106.

(66) Tomasi, J.; Mennucci, B.; Cammi, R. Quantum Mechanical Continuum Solvation Models. Chem. Rev. 2005, 105 (8), 2999-3093.

(67) Reed, A. E.; Weinstock, R. B.; Weinhold, F. Natural Population Analysis. J. Chem. Phys. 1985, 83 (2), 735-746.

(68) Marenich, A. V.; Cramer, C. J.; Truhlar, D. G. Universal Solvation Model Based on Solute Electron Density and on a Continuum Model of the Solvent Defined by the Bulk Dielectric Constant and Atomic Surface Tensions. J. Phys. Chem. B 2009, 113 (18), 6378-6396. 